\title{
Capacitação do educador acerca do abuso sexual infantil ${ }^{1}$
}

\author{
Rachel de Faria Brino \\ Lúcia Cavalcanti de Albuquerque Williams \\ Universidade Federal de São Carlos
}

\begin{abstract}
Resumo
A violência por abuso sexual é mais difícil de ser identificada por não apresentar, na maioria dos casos, marcas físicas. Capacitar professores a ser mais sensíveis aos sintomas que uma criança sexualmente abusada apresenta, talvez garanta o diagnóstico precoce destes casos. $\mathrm{O}$ estudo teve como objetivo avaliar a eficácia de uma intervenção com educadoras no sentido de capacitá-las a atuarem com casos de abuso sexual. As participantes foram 11 educadoras, sendo que 5 participaram da intervenção e 6 formaram um grupo controle. A intervenção foi composta de duas etapas: 1) Quatro encontros de três horas de duração cada um, realizados na Secretaria Municipal de Educação do município. As atividades realizadas nos encontros consistiram de exposições orais sobre o tema, atividades práticas, exposições sobre a legislação, apresentações de vídeos e filmes, role-playing etc; 2) Período de consultoria. Ao início, ao final dos encontros e após o período de consultoria foram aplicados nas participantes dois instrumentos para avaliar o desempenho destas, o RAS (Registro sobre Abuso Sexual) e o Questionário sobre Conhecimentos e Crenças a respeito de Abuso Sexual. De forma geral, a intervenção promoveu algumas importantes modificações para que as professoras atuem com casos de abuso sexual.
\end{abstract}

Palavras-chave: Abuso sexual; professores; intervenção.

\begin{abstract}
Training teachers on child sexual abuse

The violence of sexual abuse is more difficult to identify, as in the majority of cases, physical evidence is not present. If teachers were trained to be more sensitive to other symptoms that a sexually abused child shows, perhaps these children could be identified earlier. The goal of this study was to evaluate the effectiveness of an intervention program which enables teachers to work with sexual abuse cases. Participants were 11 teachers; five took part in the intervention program and six remained with a control group. The intervention program had two phases: 1) Four meetings, each of three hours duration, conducted at the Municipal School Board. Activities of this phase involved: oral presentations about the theme, practical activities, explanations about pertinent legislation, video and film presentations, role-playing, etc. 2) A consultation period. Two measurements evaluated the teachers ' performance: the RAS (Register on Sexual Abuse) and a Questionnaire regarding knowledge and beliefs on sexual abuse. Such measurements were applied before the intervention, at its end and then at the termination of the consultation phase. In general, the intervention resulted in some important changes for the teachers, enabling them to work with sexual abuse cases.
\end{abstract}

Keywords: Sexual abuse; teachers; intervention.

A violência por abuso sexual é mais difícil de ser identificada por não apresentar, na maioria dos casos, marcas físicas. Capacitar profissionais envolvidos com a questão talvez possa garantir a identificação precoce de vítimas. Fagot, Hagan, Youngblade e Potter (1989) propuseram que educadores fossem capacitados a serem mais sensíveis aos sintomas que uma criança sexualmente abusada apresenta. No entanto, é bastante raro encontrar educadores com capacitação acerca do abuso sexual e esta é claramente uma questão merecedora de estudos (Fagot, Hagan, Youngblade \& Potter, 1989; Deblinger \& Heflin, 1994).

Hazzard e Rupp (1986) encontraram que, dentre vários grupos de profissionais, os professores são os que detêm menor repertório de informações sobre abuso sexual, sugerindo a necessidade de se levantar quais informações esses professores têm acerca do abuso sexual e assim, propor e desenvolver formas de melhorar esse repertório de informações.
Há várias questões sendo estudadas na pesquisa sobre abuso sexual. Por exemplo, o impacto de cenas de um filme sobre abuso sexual em comportamento agressivo de adolescentes. Tal estudo apontou que assistir a filmes com conteúdo violento sobre abuso sexual pode ser mais um fator que contribui para a agressividade entre os adolescentes (Gomide \& Sperancetta, 2002). Outros estudos apontam os sintomas apresentados por uma criança que sofre abuso sexual, sendo que há um certo grau de consenso entre os estudiosos sobre tais sintomas. Uma criança que sofre abuso sexual pode apresentar: altos níveis de ansiedade, distúrbios no sono, distúrbios na alimentação, distúrbios no aprendizado, comportamento agressivo, apatia ou isolamento, comportamento tenso (estado de alerta), regressão a comportamento infantil, tristeza, abatimento profundo, comportamento sexualmente inapropriado para sua idade, faltas frequientes à escola, desconfiança de adultos, choro sem causa aparente, 
entre outros (Meichenbaum, 1994; Monteiro, Abreu \& Phebo, 1997; Williams, 2002). Apesar dos sintomas arrolados, a investigação sobre a capacitação de educadores para lidar com estas crianças é um esforço bastante raro. A discussão acerca da questão do abuso sexual parece ainda não ter chegado às salas de aula em termos da realidade brasileira.

Hazzard (1984) capacitou e avaliou professores de pré-escola por meio de um programa sobre prevenção do abuso sexual, composto por um workshop que incluiu apresentações didáticas, discussões em grupos, apresentações de videoteipes, role-play, período de perguntas e respostas e apresentação de representantes de agências de proteção à criança. A avaliação do programa mostrou que os professores que participaram, em comparação a um grupo controle que não recebeu a capacitação, aumentaram significativamente o conhecimento sobre abuso sexual; no entanto eles não passaram a denunciar mais casos aos Serviços de Proteção à Criança.

Desta maneira, é preciso conhecer os direitos da criança, pois uma consciência clara destes corresponde a uma maior sensibilidade para reconhecer os casos de abuso. Mas apenas conhecer não basta, é preciso saber denunciar, lidar com a criança que foi abusada, dando-lhe suporte e apoio e encaminhá-la para tratamentos especializados.

Cunningham e Sas (1995) apontam alguns fatores que podem inibir a denúncia do professor sobre a ocorrência de abuso sexual: conflitos emocionais e desconforto com a hipótese de abuso sexual; a solicitação de segredo vindo da criança; incerteza de informações que somente serão obtidas após a denúncia; o fato destes não estarem familiarizados com os procedimentos adotados pela polícia; apreensão sobre reações parentais negativas e falta de habilidades quando questionados sobre a denúncia.

Behana e Koblinsky (1984) apontam para quatro componentes que devem ser incluídos em treinamento de profissionais acerca do abuso sexual, como forma de garantir modificações nas ações e nos procedimentos utilizados pelos profissionais em relação às denúncias e encaminhamentos de casos de abuso sexual. São estes: apresentar informações básicas sobre abuso sexual, ressaltar a severidade do problema, apresentar estratégias efetivas de prevenção e apresentar métodos para detecção e manejo de casos de abuso sexual.

O conhecimento aprofundado da legislação, no caso do Brasil, do Estatuto da Criança e do Adolescente (Brasil, 1990), certamente seria um quinto componente fundamental a ser incluído em cursos de treinamento de profissionais (Brino \& Williams, 2003).

A capacitação de educadores estaria contemplando a prevenção secundária, que tem como objetivo a detecção de crianças e adolescentes em situação de risco ao seu desenvolvimento, impedindo os atos violentos e/ou suas repetições, atuando em situações já existentes e prevenindo possíveis seqüelas.

O que se pretende, em última análise, é a busca de soluções e intervenções para o grave problema da violência sexual e, após o convívio familiar, a escola mostra-se como situação ideal para detecção e intervenção junto aos casos de abuso sexual. Esta afirmação explica-se pelo contato próximo e pelo considerável período de tempo em que a instituição, a criança e seus familiares interagem (Wurtele, 1987). Cunningham e Sas (1995) conduziram um estudo em que, em $44 \%$ dos casos de abuso sexual o professor era a primeira pessoa a saber, e em $52 \%$ dos casos era o primeiro adulto a saber, demonstrando o importante papel do professor na denúncia sobre a ocorrência de abuso sexual.

Estudos acerca da violência envolvendo o sistema educacional parecem trazer elementos preciosos para as autoridades, como forma de amenizar as consequiências produzidas por esta problemática. De forma geral, violência e sexualidade são temas pouco tratados nos currículos de cursos superiores ou na formação de professores:

\begin{abstract}
Associando-se a falta de clareza nos conceitos a uma ignorância quase completa a respeito da legislação e das atribuições das diferentes instituições e áreas de conhecimento sobre o assunto, temos como resultado profissionais totalmente despreparados para enfrentar os casos reais que se apresentam, temerosos em se posicionar diante destes e receosos de que o encaminhamento de uma suspeita resulte em algum tipo de inconveniente legal para o profissional (Lerner, 2000, p. 16).
\end{abstract}

Enquanto os estudiosos da área parecem ter chegado a um consenso sobre os sintomas que uma criança que sofreu abuso sexual apresenta, educadores, conselheiros tutelares e profissionais da saúde ainda não estão capacitados para identificar o fenômeno da violência infantil e tão pouco para lidar com ele (Caminha, 1999). Diante de tal situação, parece pertinente um estudo com o seguinte objetivo: avaliar a eficácia de um curso de capacitação com educadoras, no sentido de aumentar seu repertório de informações sobre abuso sexual infantil, modificando crenças inadequadas sobre o assunto e identificando procedimentos corretos frente a denúncias e encaminhamentos de casos de abuso sexual.

Cabe ressaltar a importância de se treinar um profissional para identificar cuidadosamente os casos de abuso sexual, procedendo a um encaminhamento correto da criança e não somente promovendo denúncias, sem tomar os devidos cuidados.

\section{MÉTODO}

Participantes: Onze educadoras de Escolas Municipais de Ensino Infantil - EMEIS da cidade de São Carlos participaram do estudo. Para maximizar a adesão das educadoras foi enviada uma proposta de treinamento em serviço à Secretaria de Educação Municipal, em que as educadoras seriam liberadas das respectivas atividades para participar do curso de capacitação. Entretanto, após diversas reuniões com a Secretaria de Educação, não houve autorização para tal estratégia. Dentre as 11 participantes, cinco 
aceitaram participar da intervenção e compareceram a todos os encontros (tendo $100 \%$ de presença). O grupo que recebeu intervenção (GI) foi composto por cinco participantes com idade entre 31 e 50 anos e o grupo controle (GC) foi composto por seis participantes com idade entre 32 e 60 anos.

Equipamento e material: Foram utilizados protocolos para os instrumentos de avaliação, transparências com o conteúdo abordado, televisão, vídeo-cassete e retro-projetor.

Local: O local dos encontros foi uma sala da Secretaria Municipal de Educação.

Instrumento de coleta de dados: Foi utilizado o Registro sobre Abuso Sexual (RAS) (ver Anexo A) com os seguintes tópicos: 1) identificar um caso suspeito de abuso sexual na classe; 2) encaminhar um caso suspeito de abuso sexual na classe para o Conselho Tutelar, Delegacia da Mulher ou outra autoridade competente; 3) falar com a criança sobre a suspeita de abuso sexual; 4) fazer uma apresentação na classe sobre abuso sexual; 5) discutir abuso sexual com colegas de trabalho na escola; 6) leitura de materiais relacionados ao abuso sexual. Tal instrumento consistiu em uma tradução pelas autoras de um instrumento utilizado por Hazzard em 1984. Adicionalmente, foi elaborado para o estudo um Questionário sobre Conhecimento e Crenças a Respeito de Abuso Sexual composto por 43 afirmações acerca do abuso sexual, a serem assinaladas com verdadeiro ou falso.

Procedimento: Para a realização da intervenção, foi feito por carta um pedido de autorização à prefeitura e à direção da escola, juntamente com a solicitação para as entrevistas. A intervenção foi composta de duas partes, sendo que a primeira correspondeu a um curso de capacitação e a segunda constituída por uma consultoria. No curso de capacitação, as participantes compareceram a quatro encontros quinzenais, semelhantes a um workshop, de três horas de duração cada encontro, sendo de livre escolha o comparecimento ou não. Foi confirmado, por telefone, com cada uma a presença nos dias e horários pré-estabelecidos. As atividades realizadas no Curso de Capacitação consistiram de apresentações e exposições orais sobre o tema, discussões em grupo, role-play, estudos de caso, apresentação de filmes e vídeos, orientações gerais sobre abuso sexual e sobre a legislação, sugestões de leituras pertinentes ao tema e espaço para dúvidas e comentários.

\section{Planejamento da intervenção}

Objetivo Geral: Capacitar professores a atuar adequadamente com casos de suspeita de abuso sexual entre seus alunos.

\section{Objetivos específicos:}

- Discorrer acerca do tema abuso sexual contra crianças.

- Identificar normas e leis do ECA (Estatuto da Criança e do Adolescente) no que se refere a abuso sexual.

- Refletir sobre os procedimentos adotados pelo profissional diante de um caso de abuso sexual.

- Identificar formas de ação na situação de ocorrência de abuso sexual, principalmente quando a vítima for uma criança de sua classe.

Os tópicos discutidos, listados abaixo, foram baseados em entrevistas conduzidas com as professoras em estudo anterior (Brino \& Williams, 2003) e em estudos sobre treinamento de professores (Hazzard, 1984; Hazzard \& Rupp, 1986; Cunningham \& Sas, 1995; Behana \& Koblinsky, 1984; Haugaard \& Rep-pucci, 1989):

- Definições de abuso sexual infantil;

- Crenças (mitos e realidades);

- Causas e conseqüências (efeitos) do abuso sexual;

- Aspectos legais do abuso sexual (Estatuto da Criança e do Adolescente);

- Deveres do profissional frente a estes casos;

- Encaminhamento e tratamento da criança sexualmente abusada.

Foi dado às professoras um incentivo à participação nos encontros: no primeiro encontro foi entregue um brinde (produtos de higiene e beleza) a cada participante e nos demais foi sorteado um brinde diverso entre as participantes presentes.

Com a impossibilidade de todas as professoras estarem participando dos encontros, embora não tendo sido inicialmente planejado, foi possível a obtenção de dois grupos, sendo um grupo de professoras que participou do curso de capacitação (grupo "experimental", $\mathrm{n}=5$, composto pelas participantes 1 , $2,3,4$ e 5) e um grupo de professoras que não participou da intervenção (um grupo "controle" $n=6$, composto pelas participantes $6,7,8,9,10$ e 11). Cabe lembrar, entretanto, que não se trata de um delineamento de grupo típico, dado o número pequeno de participantes e a ausência de randomização das participantes.

Ao início dos encontros foi obtida uma linha de base para o grupo que recebeu a intervenção e para o que não recebeu (grupo "controle") com a aplicação dos instrumentos.

A segunda fase da intervenção consistiu de um período, denominado consultoria, em que foram realizadas reuniões semanais, individuais, com as

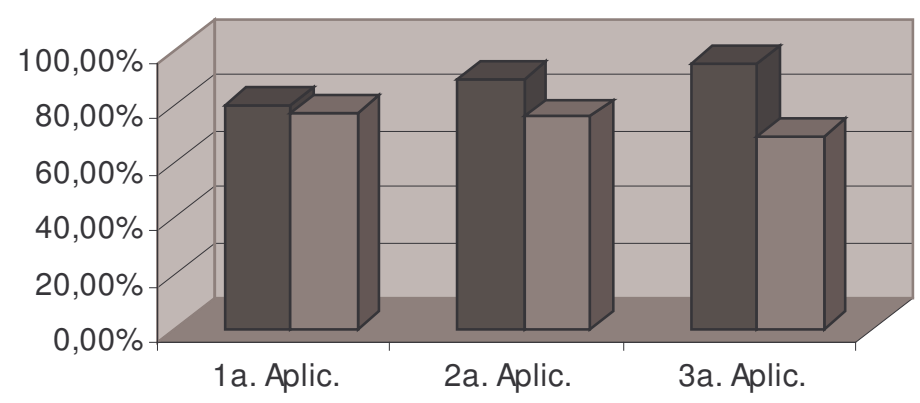


professoras. Em tais reuniões eram discutidas questões referentes ao abuso sexual, além da análise de casos suspeitos. Quando era identificada uma suspeita, a primeira autora acompanhava uma aula, procurando observar os comportamentos da criança juntamente com a professora. O caso suspeito era encaminhado, em conjunto, para serviços de apoio psicológico e órgãos responsáveis pelo atendimento a criança vítima de maus-tratos. Após os encaminhamentos, foram feitas consultas às professoras, periodicamente, por telefone, para averiguar o andamento dos casos encaminhados.

Após o período de consultoria, foi realizado um último encontro com as participantes para apresentação dos dados obtidos e dos resultados alcançados com o estudo.

O RAS foi aplicado individualmente, em todas as educadoras, durante 10 minutos, antes do primeiro encontro e após o último encontro, na sala em que se realizou o curso. Além disso, o mesmo instrumento foi aplicado novamente após o período de consultoria.

O Questionário sobre Conhecimento e Crenças a Respeito de Abuso Sexual foi aplicado individualmente, durante 15 minutos, antes do primeiro encontro e depois do último encontro, na sala em que se realizou o curso, nas participantes em conjunto. Além disso, foi aplicado novamente após o período de consultoria.

\section{RESULTADOS E DISCUSSÃO}

\author{
Desempenho das Professoras no Questionário \\ sobre Conhecimento e Crenças a respeito de \\ Abuso Sexual.
}

A porcentagem média de acertos no questionário, nos dois grupos (GI e GC), nas três aplicações diferentes está apresentado na Figura 1 abaixo. Para o grupo que recebeu intervenção (GI), a variação da porcentagem de acertos foi de $74,4 \%$ a $83,72 \%$ na $1^{\mathrm{a}}$. aplicação do questionário e de $93 \%$ a $100 \%$ após o período de consultoria. Para o grupo controle (GC), a variação da porcentagem de acertos variou de $65,10 \%$ a $90,70 \%$ na primeira aplicação do questionário para $51 \%$ a $88,3 \%$ após o período de consultoria.

Figura 1: Porcentagem média de acertos no questionário entre as participantes.

De forma geral, todas as participantes que receberam a intervenção (GI), aumentaram a porcentagem de respostas corretas entre a $1^{\mathrm{a}}$ e a $2^{\mathrm{a}}$ aplicação e também da $2^{\mathrm{a}}$ para a $3^{\mathrm{a}}$ aplicação, sendo que na fase pré-intervenção a porcentagem de acertos já era alta, variando de $74,4 \%$ a $83,72 \%$. No entanto esta melhora foi discreta, variando entre 9,3\% (P1-GI) e $19 \%$ (P4-GI).

Foi realizada uma avaliação da significância de diferenças entre os três tratamentos por meio do teste de Friedman (não-paramétrico). A significância das diferenças pode ser verificada pela comparação do valor calculado de Q, com o valor do quartil correspondente da distribuição exata ou aproximada. Nos casos em questão, há seis e cinco indivíduos (grupos intervenção e controle), e três tratamentos para cada grupo (correspondente à média para os grupos de cada aplicação do questionário, respectivamente $1^{\mathrm{a}}, 2^{\mathrm{a}}$ e $3^{\mathrm{a}}$ aplicação).

A média do GI teve um aumento progressivo com o decorrer do estudo aumentando de $80,46 \%$ na $1^{\mathrm{a}}$ aplicação para $89,75 \%$ na $2^{\mathrm{a}}$ e para $94,86 \%$ na $3^{\mathrm{a}}$. Para o grupo intervenção, a probabilidade de significância ou valor-p correspondente à comparação de três tratamentos foi 0.0067 , o que corresponde a uma forte evidência de que existe diferença entre os tratamentos. Seguindo para a verificação de diferenças entre pares de tratamentos, pelo valor-p correspondente, 0.029, verificou-se que existe diferença significativa entre os tratamentos 1 e 3 ( $1^{\mathrm{a}}$ e $3^{\mathrm{a}}$ aplicação). Encontrou-se forte evidência na amostra de que o número de respostas certas na $1^{\mathrm{a}}$ aplicação foi menor do que na $3^{\mathrm{a}}$ aplicação. O valor-p correspondente 0.029 indica que se encontrou diferença significativa entre os tratamentos 2 e 3 ( $2^{\mathrm{a}}$ e $3^{\mathrm{a}}$ aplicação). Observou-se forte evidência na amostra de que o número de respostas certas na $2^{\mathrm{a}}$ aplicação foi menor do que na $3^{\mathrm{a}}$. Finalmente, o valor-p correspondente 0.029 indica que se encontrou diferença significativa entre a $1^{\mathrm{a}}$ e a $2^{\mathrm{a}}$ aplicação. Constatou-se forte evidência na amostra de que o número de respostas certas na $2^{\mathrm{a}}$ aplicação foi maior do que na $1^{\mathrm{a}}$.

No grupo controle (GC), a média entre as participantes manteve-se a mesma da $1^{\mathrm{a}}$ aplicação para a $2^{\mathrm{a}}$ aplicação do instrumento, sendo que houve um decréscimo no desempenho médio da $2^{\mathrm{a}}$ aplicação para a $3^{\mathrm{a}}$. A média do GC decresceu de 77,5\% na primeira aplicação para $75,95 \%$ na segunda aplicação e para $69,3 \%$ na $3^{a}$. Para o grupo controle, a probabilidade de significância ou valor-p correspondente à comparação dos três tratamentos foi 0.0083, o que corresponde a uma forte evidência de que houve diferença entre os tratamentos. Seguindo para a verificação entre pares de tratamento, pelo valor-p correspondente, 0.018 , verificou-se que existe diferença significativa entre os tratamentos 1 e $3\left(1^{\mathrm{a}} \mathrm{e}\right.$ $3^{\mathrm{a}}$ aplicação). Mais precisamente, encontrou-se forte evidência na amostra de que o número de respostas certas na $1^{\mathrm{a}}$ aplicação foi maior do que na $3^{\mathrm{a}}$. O valor$\mathrm{p}$ correspondente, 0.033 , indica que foi encontrada uma diferença significativa entre os tratamentos 2 e 3 $\left(2^{\mathrm{a}}\right.$ e $3^{\mathrm{a}}$ aplicação). Mais precisamente, encontrou-se forte evidência na amostra de que o número de respostas certas na $2^{\mathrm{a}}$ aplicação foi maior que na $3^{\mathrm{a}}$. Entretanto, o valor-p correspondente 0.055 , não permite afirmar que exista diferença significativa entre as duas primeiras aplicações $\left(1^{\mathrm{a}}\right.$ e $2^{\mathrm{a}}$ ocasiões $)$. Não houve, portanto, evidência suficiente na amostra para afirmar que o número de respostas certas na $1^{\mathrm{a}}$ aplicação foi maior que na $2^{\mathrm{a}}$ aplicação. 
Em resumo, os desempenhos apresentados na Figura 1 permitem concluir que as participantes do grupo que recebeu intervenção apresentaram um aumento em seu repertório de informações acerca do abuso sexual infantil, enquanto que aquelas que não se dispuseram a participar da intervenção, mantiveram seu repertório inalterado ou apresentaram um decréscimo neste.

\section{Desempenho das participantes no Registro sobre Abuso Sexual (RAS)}

Os desempenhos apresentados pelas participantes no RAS demonstram uma discreta mudança nos procedimentos e encaminhamentos referentes a casos de abuso sexual apresentados pelas participantes do grupo que recebeu intervenção, enquanto que as participantes do grupo controle apresentaram manutenção dos procedimentos e encaminhamentos registrados nas duas aplicações do RAS.

Com relação ao primeiro item do RAS, a identificação de casos, em ambos os grupos, os registros mantiveram-se estáveis. Nenhuma participante passou a identificar casos de abuso sexual após a intervenção, o que permite levantar duas hipóteses explicativas: a) possivelmente não tenha havido casos de abuso sexual nas classes e, portanto, as professoras não tiveram oportunidade de identificálos, sendo tal hipótese fortalecida pelo fato da intervenção ter tido duração de um mês, período bastante exíguo e/ou b) as participantes não desenvolveram um repertório que as tornasse capazes de identificar casos de abuso sexual após receberem o treinamento, ou seja, as informações que receberam e o treino não foram suficientes para capacitá-las a identificar casos de abuso sexual.

Ainda com relação à identificação de casos, ao comparar o grupo controle com o que recebeu intervenção, pode-se notar que na primeira aplicação do instrumento, no grupo que recebeu intervenção, uma participante já havia identificado casos de abuso sexual, e no grupo controle, nenhuma participante havia identificado.

Os estudos de Hazzard (1984) e Kleemier e cols. (1987), citados por Haugaard e Reppucci (1989), apontaram resultados semelhantes, sendo que os professores treinados não passaram a identificar, após a intervenção, novos casos de abuso sexual. No entanto, o estudo de Swift (1983), mencionado por Haugaard e Reppucci (1989), com enfermeiras e orientadores educacionais, apontou um crescimento bastante considerável na identificação de casos de abuso sexual por parte destes profissionais, após terem participado da intervenção. Cabe ressaltar que enfermeiras em grandes centros hospitalares provavelmente deparam-se diariamente com um número maior de casos de abuso sexual do que professoras, além de terem acesso a exames freqüentes da criança. Orientadores educacionais também têm, segundo a hierarquia da escola, maior possibilidade de estarem relatando um caso de abuso sexual, que pode até ter sido identificado pela professora, mas que sendo encaminhado ao orientador, coube a ele proceder à descrição do caso.

Se por um lado, as professoras do GI não identificaram e não encaminharam um maior número de casos de abuso sexual após a intervenção, estas passaram, entretanto, a solicitar auxílio para encaminhar casos suspeitos aos órgãos competentes. Todavia, por alguma razão, tal pedido de consultoria não foi registrado pelas professoras no RAS. Algumas especulações sobre essas razões apontam para o fato de que, talvez por serem apenas suspeitas de casos de abuso sexual, as professoras não tenham entendido como sendo uma identificação, concluindo que somente a comprovação da ocorrência poderia ser entendida como identificação efetiva.

Para o grupo que recebeu a intervenção, segundo o registro no RAS, uma participante procedeu a um encaminhamento de caso de abuso sexual após a intervenção, sendo que na fase pré-intervenção não havia sido feito encaminhamento de casos de abuso sexual. Parece ser possível concluir que tal encaminhamento foi realizado somente após a participante ter recebido o treinamento, sendo este responsável pelos procedimentos e encaminhamentos feitos pela participante. No grupo controle (nas duas aplicações do RAS) nenhuma participante encaminhou casos de abuso sexual, o que parece coerente com o primeiro item, de identificação; ou seja, se não houve identificações, também não poderia haver encaminhamento. Por outro lado cabe relembrar a hipótese levantada referente ao período exíguo de tempo em que se desenvolveu o treinamento, sendo necessários outros estudos para confirmar tal hipótese.

Com relação ao registro de encaminhamentos feito pelas participantes no RAS, o número pequeno de encaminhamentos pode estar relacionado aos aspectos apontados por Lerner (2000), já mencionados neste texto. Esta lacuna na formação e no conhecimento do profissional acerca da legislação e de outros assuntos ligados ao tema pode não ser preenchida com um breve curso de capacitação (embora este tenha estabelecido um "ponto de partida" para tratar a questão), sendo, talvez, necessário um programa intensivo de treinamento. Tudo leva a crer que a medida ideal envolveria a incorporação de tais questões aos currículos de formação destes profissionais, o que não deixa de ser uma tarefa complexa.

Quanto ao terceiro item do RAS, "conversas com a criança sobre a suspeita de abuso", houve uma modificação da primeira para a segunda aplicação no grupo que recebeu a intervenção: enquanto na primeira aplicação apenas uma participante disse ter conversado uma vez com a criança sobre a suspeita, na segunda uma disse ter conversado uma vez e outra disse ter conversado duas vezes. Parece ser possível concluir que, após a intervenção, algumas participantes passaram a suspeitar da ocorrência de casos de abuso sexual (sem no entanto considerar isto como uma identificação de novos casos, como visto no item anterior), procedendo, então, a uma conversa com a criança para averiguar a veracidade da suspeita. No entanto, relacionando esta conclusão aos itens 
anteriores, as professoras parecem não ter feito encaminhamentos referentes às conversas com a criança sobre a suspeita, o que permite concluir que: a) os professores não foram capazes de proceder ao encaminhamento correto, ou b) as participantes não consideraram como sendo plausível a história relatada pela criança. Para o GC, a conclusão provavelmente refere-se ao fato de as participantes não terem acesso a informações de como identificar e aproximar-se de uma criança suspeita de ter sido abusada sexualmente, ou talvez que realmente não tenha havido casos de abuso sexual em suas classes. Este registro sobre nunca ter conversado com uma criança sobre a suspeita de abuso, tanto na primeira quanto na segunda aplicação do instrumento, é condizente com os registros dos itens anteriores, ou seja, se nunca identificaram e não encaminharam casos, também não foram realizadas conversas com a criança sobre a suspeita de abuso sexual.

Em relação ao próximo item, “fazer uma apresentação para as crianças da classe sobre abuso sexual", no grupo que recebeu intervenção, houve uma modificação nos registros da primeira para a segunda aplicação do RAS: uma participante passou a fazer uma apresentação para a classe com freqüência anual após a intervenção (ou seja, como a intervenção durou apenas uma mês, pode-se concluir que ela fez uma apresentação durante o período, sendo equivalente à frequiência anual), parecendo ser possível concluir que a intervenção foi responsável por essa mudança de procedimento adotado pela participante. Em relação ao grupo controle, nenhuma participante apresentou modificação no procedimento adotado (sendo que nenhuma realizou apresentações para a classe), considerando-se o primeiro e o segundo registro do RAS, sendo possível concluir que as participantes do GC não tiveram acesso a informações sobre procedimentos adequados para lidar com a prevenção e ocorrência do abuso sexual, talvez por não se sentirem suficientemente motivadas.

Para o item referente a "discutir o tema com colegas de trabalho", no grupo que recebeu intervenção, as participantes passaram a discutir o tema com as colegas de trabalho com mais frequiência se forem considerados os registros antes e depois da intervenção, o que torna provável a conclusão de que a intervenção possibilitou essa modificação. Para o grupo controle, as participantes mantiveram a mesma frequiência nas discussões do tema com as colegas de trabalho da primeira para a segunda aplicação do RAS.

Finalmente, com relação ao último item, "leitura de materiais sobre o assunto", no grupo que recebeu intervenção, as participantes passaram a realizar leituras sobre o tema com mais freqüência após receberem a intervenção, enquanto que no grupo controle, as participantes mantiveram a frequiência de leitura de materiais sobre o tema. Tudo leva a crer que a intervenção promoveu um maior interesse entre as participantes em relação à leitura de materiais sobre o assunto.

\section{Terceira aplicação do Registro sobre Abuso Sexual}

Com relação à "identificação de casos de abuso sexual", dentre as participantes do grupo que recebeu a intervenção, duas participantes afirmaram ter feito uma identificação cada e uma participante afirmou ter feito três identificações de casos. Para o grupo controle, todas as participantes afirmaram nunca ter identificado casos de abuso sexual.

No que se refere aos "encaminhamentos", no grupo que recebeu intervenção, duas participantes afirmaram ter feito um encaminhamento cada e uma participante afirmou ter feito três encaminhamentos. Para o grupo controle, todas as participantes afirmaram nunca ter encaminhado casos de abuso sexual.

Em relação à "conversas com a criança sobre a suspeita de abuso sexual", no grupo que recebeu intervenção, duas participantes mantiveram três conversas com crianças suspeitas de abuso sexual e uma participante manteve uma conversa. Para o grupo controle, todas as participantes afirmaram nunca ter realizado conversas com crianças suspeitas de abuso sexual.

Em relação à "fazer uma apresentação para as crianças de sua classe", três participantes afirmaram fazê-lo semestralmente, uma mensalmente e uma outra semanalmente. No grupo controle, todas afirmaram não fazê-lo.

No registro de frequiência de "discussões sobre o tema com colegas de trabalho", três participantes do GI afirmaram fazê-lo mensalmente e duas semanalmente. No grupo controle, todas afirmaram não fazê-lo.

Finalmente, com relação à "leitura de materiais sobre o tema", no GI todas as participantes afirmaram fazê-lo semanalmente e todas do GC afirmaram não fazê-lo.

Nos itens de "identificação e encaminhamento", três professoras identificaram e encaminharam cinco casos de abuso sexual, o que parece demonstrar que o tempo transcorrido após o término da intervenção possibilitou que elas refletissem sobre os assuntos abordados no curso e pudessem promover ações mais efetivas. No grupo controle nenhuma participante identificou ou encaminhou casos.

Nos demais itens do RAS, os registros demonstram um aumento da freqüência de realização das ações em questão, sendo possível afirmar que o curso possibilitou uma maior reflexão sobre o tema e propiciou mudanças efetivas nas ações das professoras. No grupo controle nenhuma participante registrou ter feito alguma ação em questão.

Cabe ressaltar que as diferenças entre as duas primeiras aplicações não foram significativas, e que a diferença entre a primeira e a terceira foram significativas, o que torna possível concluir que o período de consultoria às professoras foi responsável pelas mudanças significativas.

A avaliação do curso de capacitação apontou para aspectos bastante positivos, como uma melhora no repertório de informações acerca do abuso sexual 
entre as participantes, e principalmente para a existência de encaminhamentos de crianças suspeitas de abuso sexual para Serviços de Psicologia e para os órgãos competentes. Tais aspectos parecem indicar que o curso de capacitação, ainda que breve, promoveu acréscimo às informações que as participantes detêm sobre abuso sexual, além de promover ações adequadas frente à suspeita de abuso sexual. Cabe ressaltar a relevância de se fazer encaminhamentos de casos de suspeita de abuso sexual, pois isto significa que crianças em situação de risco ao seu desenvolvimento estão sendo protegidas por órgãos de apoio, sendo possível o alívio ou a amenização de seu sofrimento. Adicionalmente, tudo leva a crer que as professoras que participaram do curso tornaram-se multiplicadoras das informações obtidas e das ações aprendidas e praticadas, servindo em várias ocasiões, como modelo para outras professoras envolvidas com a questão.

Do ponto de visto metodológico, três aspectos do estudo merecem destaque: a) as participantes não foram distribuídas aleatoriamente entre os grupos, pois o fator determinante foi à própria disponibilidade de cada uma em estar participando da intervenção; b) as participantes do GI já na primeira aplicação do questionário apresentaram um patamar alto em relação à percentagem de acertos, variando entre $70 \%$ e $90 \%$ de acertos, sendo este um fator que provavelmente impediria mudanças drásticas na segunda aplicação do questionário; e c) o número reduzido de participantes é um fator de limitação do estudo, sendo necessário replicar os resultados com um número maior de participantes.

Os resultados relacionados aos desempenhos apresentados pelas participantes de ambos os grupos (GI e GC) no questionário demonstraram que as participantes, já na primeira aplicação do questionário, apresentaram porcentagem de acertos acima de 60\%, porém as do GI apresentaram desempenho superior aos das participantes do grupo controle (GC), permitindo concluir que as primeiras apresentavam melhor repertório de informações que as outras. Essa conclusão parece demonstrar que as professoras que se dispuseram a participar da intervenção, ou seja, aquelas motivadas a participar, apresentavam melhor repertório de informações do que aquelas que não se dispuseram a participar. Cabe ressaltar a importância e necessidade de realizar a intervenção mesmo considerando que todas as participantes apresentaram porcentagem de acertos maior do que $60 \%$, pois, muitas vezes, apenas um repertório de informações razoável não garante que o professor realize o procedimento adequado. Desta forma, a garantia de uma melhora no repertório de informações, tornandoo mais completo, pode contribuir para ações mais eficazes e adequadas.

A intervenção apresentou alguns pontos fortes, e outros que poderiam ser aprimorados. A realização de um grupo pequeno e os atendimentos individualizados às professoras permitiram uma discussão mais aprofundada dos assuntos tratados, além de identificar e procurar esclarecer problemas práticos e cotidianos com os quais cada professora se depara. As atividades práticas desenvolvidas, como simulações de situações e palestras para outras colegas de trabalho, auxiliaram no processo de aprendizagem de como proceder na situação real. As aulas expositivas, por sua vez, auxiliaram como suporte para compreender as ações adequadas a serem tomadas.

Para a realização de futuras intervenções parece importante que sejam incluídas novas atividades práticas como observação e registro de sintomas apresentados pelas crianças da classe da professora (tais como grau de socialização e envolvimento em atividades de ensino e lúdicas, rendimento escolar em trabalhos, relações interpessoais, comportamentos para resolução de conflitos, presença nas aulas diárias, reação a adultos e aos responsáveis pela criança, entre outros) e posterior análise para aprendizado de identificação de casos de suspeita de abuso sexual. Com relação ao período de realização da intervenção parece que o início deveria ocorrer cerca de um a dois meses após o início das aulas, quando o professor já está familiarizado com a criança, podendo então identificar comportamentos problemáticos. Uma intervenção com um tempo de duração mais longo e com encontros semanais poderia acarretar em modificações importantes, considerando-se que mudanças mais significativas são obtidas em longo prazo. Devido a inúmeras dúvidas sobre os procedimentos adotados pelos Conselhos Tutelares e o receio de denunciar casos, parece importante propor, em futuras intervenções, que um representante do Conselho Tutelar ou do Juizado da Vara da Infância e Adolescência possa participar de um encontro para expor o trabalho desenvolvido com as crianças e esclarecer dúvidas.

A análise dos resultados (principalmente considerando-se a $3^{\text {a }}$ aplicação) indicou que o RAS apresentou-se como um instrumento adequado $\mathrm{e}$ suficientemente sensível para detectar mudanças nas ações das professoras, se aplicado entre intervalos maiores de tempo.

\section{CONSIDERAÇÕES FINAIS}

A relevância social e a importância de se produzir conhecimento novo na área de abuso sexual infantil parecem ser inquestionáveis, principalmente no que se refere à investigação de aspectos relacionados à intervenção e que podem ser aplicados como forma de se prevenir ou amenizar as conseqüências da ocorrência de casos de abuso sexual infantil.

Alguns percalços são encontrados nas investigações desta área de estudo, parecendo ser o mais freqüente a dificuldade de se obter adesão dos participantes (o que se deve ao assunto ainda ser considerado "tabu", bem como à falta de tempo e disponibilidade para estar participando de cursos no horário de folga) o que dificulta a abrangência dos resultados finais, sendo necessário novas investigações que contemplem um maior número de participantes. 
Para que se possa obter uma maior adesão dos participantes, faz-se necessário o apoio de órgãos administrativos superiores (por exemplo, a Secretaria Municipal de Educação) para que os Cursos de Capacitação possam ser feitos como treinamento em serviço, ou seja, no período de atividades das professoras. O estudo indica que a Secretaria e os participantes obteriam ganhos com tais Cursos de Capacitação em Serviço. Adicionalmente, os participantes não teriam atividades extras, sobrecarregando-os no trabalho, e a Secretaria poderia oferecer cursos de capacitação a seus professores praticamente sem custos.

Segundo os dados obtidos, muitas das professoras levariam os casos de abuso sexual ao conhecimento da direção da escola. Esse fato chama a atenção para a importância de se envolver a administração escolar em projetos de capacitação semelhantes ao presente estudo. Outro argumento que aponta para essa necessidade refere-se ao fato de que há uma hierarquia administrativa na escola, que parece ser bastante respeitada nas escolas municipais infantis, principalmente em se tratando de temas difíceis como o abuso sexual infantil.

A questão do abuso sexual relacionada à política educacional parece um aspecto importante a ser destacado. Os resultados e conclusões do estudo atual comprovam a existência de uma lacuna no conhecimento de educadores acerca das muitas facetas do abuso sexual, além da falta de um planejamento para que questões que envolvam a violência contra a criança, em todas as suas formas - incluindo a sexual sejam incluídas em currículos escolares e abordadas em cursos de Reciclagem e Aperfeiçoamento Profissional.

Essa problemática aparece bastante clara quando há dados que demonstram o desconhecimento de profissionais que trabalham diretamente com a criança acerca do Estatuto da Criança e do Adolescente (Brino, 2002; Brino \& Williams, 2003). O desconhecimento deste instrumento de apoio às professoras e às crianças demonstra a falta de envolvimento governamental em divulgar e tratar um problema social grave como a violência contra a criança, problema este em que todos os setores da sociedade necessitam se envolver.

Como último aspecto a ser considerado, cabe discutir que as crianças vítimas de abuso sexual têm necessidades educativas especiais que precisam de atendimento especializado não só porque constituem risco ao aprendizado e ao desenvolvimento, mas também porque a escola tem um compromisso com a promoção da cidadania e a qualidade de vida de sua clientela.

\section{REFERÊNCIAS}

Behana, N. \& Koblinsky, S. (1984). Child sexual abuse: The educator's role in prevention, detection, and intervention. Young Children, 39, 3-15.
Brasil. (1990). Estatuto da Criança e do Adolescente. Juiz de Fora: Universidade Federal de Juiz de Fora.

Brino, R. F. (2002). Capacitação do educador acerca do abuso sexual infantil. Dissertação de Mestrado, Programa de Pós-Graduação em Educação Especial, Universidade Federal de São Carlos. São Carlos, SP.

Brino, R. F. \& Williams, L. C. A. (2003). Concepções da professora acerca do abuso sexual infantil. Cadernos de Pesquisa: Fundação Carlos Chagas, 119, 113-128.

Caminha, R. M. (1999). A violência e seus danos à criança e ao adolescente. Em Assembléia Legislativa, Comissão de Cidadania e Direitos Humanos, Violência Doméstica (pp. 43-60). Rio Grande do Sul.

Cunningham, A. H. \& Sas, L. D. (1995). The role of school programs in disclosure. Tipping the balance to tell the secret: The public discovery of child sexual abuse. Ontario: London Family Court Clinic Inc.

Deblinger, E. \& Heflin, A. D. (1994). Child sexual abuse. Em F. M. Dattilio \& A. Freeman (Orgs.), Cognitivebehavioral strategies in crisis intervention (pp. 177197). New York: The Guilford Press.

Fagot, B. I., Hagan, R., Youngblade, L. M. \& Potter, L. (1989). A comparison of the play behaviors of sexually abused, physically abused, and nonabused preschool children. Topics in Early Childhood Special Education, 9 (2), 88-100.

Gomide, P. I. C. \& Sperancetta, A. (2002). O efeito de um filme de abuso sexual no comportamento agressivo de adolescentes. Interação em Psicologia, 6 (1), 1-11.

Haugaard, J. J. \& Reppucci, N. D. (1989). Prevention of child sexual abuse - Myth or reality. American Psychologist, 44, 1266-1275.

Hazzard, A. (1984). Training teachers to identify and intervene with abused children. Journal of Clinical Child Psychology, 13 (3), 288-293.

Hazzard, A. \& Rupp, G. (1986). A note on the knowledge and attitudes of professional groups toward child abuse. Journal of Community Psychology, 14, 219-223.

Lerner, T. (2000). Tratamento em situações de abuso sexual de crianças e adolescentes. Jornal da Rede Saúde, 22, 15-16.

Meichenbaum, D. (1994). A clinical handbook/practical therapist manual for assessing and treating adults with pos-traumatic stress disorder (PTSD). Waterloo: Institute Press.

Monteiro, L.; Abreu, V. I. \& Phebo, L. B. (1997). Abuso sexual: Mitos e realidade. Petrópolis: Autores \& Agentes \& Associados.

Williams, L. C. de A. (2002). Abuso sexual infantil. Em H. J. Guilhardi; M. B. B. P. Madi; P. P. Queiroz \& M. C. $\mathrm{Scoz}$ (Orgs.), Sobre comportamento e cognição: Contribuições para a construção da teoria do comportamento (pp. 155-164). Santo André: ESETec Editores.

Wurtele, S. K. (1987). School-based sexual abuse prevention programs: A review. Child Abuse \& Neglect, $11,483-495$. 


\section{Nota:}

${ }^{1} \mathrm{O}$ artigo compõe parte da dissertação de mestrado da primeira autora, sob orientação da segunda autora, e financiado pela Fundação de Amparo à Pesquisa do Estado de São Paulo - FAPESP.

\section{Sobre as autoras:}

Profa. Ms. Rachel de Faria Brino (Laboratório de Análise e Prevenção da Violência, Universidade Federal de São Carlos): Graduada em Psicologia pela Universidade Federal de São Carlos, Mestre em Educação Especial pela UFSCar, Doutoranda e Bolsista do CNPq em Educação Especial pela UFSCar.

Profa. Dra. Lúcia Cavalcanti de Albuquerque Williams (Laboratório de Análise e Prevenção da Violência, Universidade Federal de São Carlos): Professora da Universidade Federal de São Carlos, Pós-Doutorado em Psicologia Educacional pela Universidade de Toronto, Canadá; Doutorado em Psicologia Experimental pela USP, São Paulo; Mestrado em Psicologia pela Universidade de Manitoba, Canadá; Graduação em Psicologia pela PUC-SP.

Endereço para correspondência: Rodovia Washington Luiz, Km 235, 13560-280, São Carlos - SP

Tel: (0XX16- 260-8745) / Fax: (0XX16- 2608362) - E-mail: chelbrino@ hotmail.com 


\section{ANEXO A}

\section{Registro sobre Abuso Sexual}

Instrução: Registre, assinalando na escala suas respostas após cada pergunta solicitada.

01) Você já identificou algum caso suspeito de abuso sexual em sua classe? Se sim, quantos?

\begin{tabular}{|l|l|l|l|l|l|}
\hline 0 & 1 & 2 & 3 & 4 & Mais de 4 \\
\hline
\end{tabular}

02) Você já encaminhou um caso suspeito de abuso sexual da sua classe para o Conselho Tutelar, Delegacia da Mulher ou outra autoridade competente? Se sim, quantos?

\begin{tabular}{|l|l|l|l|l|l|}
\hline 0 & 1 & 2 & 3 & 4 & Mais de 4 \\
\hline
\end{tabular}

03) Você já conversou com a criança sobre a suspeita de abuso sexual? Se sim, quantas vezes?

\begin{tabular}{|l|l|l|l|l|l|}
\hline 0 & 1 & 2 & 3 & 4 & Mais de 4 \\
\hline
\end{tabular}

04) Você já fez uma apresentação em sua classe para as crianças sobre abuso sexual? Se sim, com qual freqüência?

\begin{tabular}{|c|c|c|c|}
\hline semanal & mensal & semestral & anual \\
\hline
\end{tabular}

05) Você já discutiu o tema abuso sexual com colegas de trabalho na escola? Se sim, com qual freqüência?

\begin{tabular}{|c|c|c|c|}
\hline semanal & mensal & semestral & anual \\
\hline
\end{tabular}

06) Você realiza leitura de materiais relacionados ao tema abuso sexual? Se sim, com qual frequiência?

\begin{tabular}{|c|c|c|c|}
\hline semanal & mensal & semestral & anual \\
\hline
\end{tabular}

Adaptado a partir de instrumento utilizado por Hazzard e Rupp (1986). 